\title{
Cardiac Myxoma- 17 Years Experience in a Tertiary Care Centre of Bangladesh
}

\author{
Subhash C Mandal ${ }^{1}$, Md. Shafiqul Islam², KSSZ Rushel ${ }^{3}$, Md. Saiful Hoque Talukder ${ }^{4}$, Md. Mesbah Uddin ${ }^{5}$, Md. Monzur \\ Hossain $^{6}$, Md. Mujibur Rahman Rony ${ }^{7}$
}

\begin{abstract}
:
Cardiac Myxoma is the most common benign intracardiac tumor of heart. We studied its incidence, clinical presentations, short term outcome, morbidity and mortality following surgery over a period of 17 years. The study was performed inthe department of cardiac surgery, National institute of Cadiovascular diseases (NICVD) Dhaka, over a period from 2000to 2016. NICVD is the tertiary hospital for cardiovascular surgery in the Government sector. Over this period of 17 years 11,923 open heart surgery was done of which 129 were cardiac myxoma patients. As a result, cardiac myxoma patients constituted $1.08 \%$ of all open heart surgery. Preoperative diagnosis was done on clinical presentations and 2D
\end{abstract}

echocardiography, which is the most important tool for its diagnosis. Most of the patients presented at $4^{\text {th }}$ to $5^{\text {th }}$ decade of life. The patients presented with triad ofvalve obstructive features, embolic symptoms andconstitutional symptoms alone or in combination. Among all myxoma patients, majority(86.6\%) had left atrial myxoma. Cardiac myxoma forms a very small percentage of all cardiac diseases requiring surgical treatment. Immediate surgical excision is indicated in all patients to avoid life-threatening complications. Outcome of surgical treatment was excellent.

Key word: Cardiac, Myxoma, Surgery, Bangladesh.

(Bangladesh Heart Journal 2017; 32(2) : 85-88)

Introduction:

Cardiac myxoma is the most common benign tumour of heart and commonly diagnosed by echocardiography.

1. Associate Professor, Dept. of Cardiac Surgery, National Institute of Cardiovascular Diseases, Sher-E-Bangla Nagar, Dhaka, Bangladesh.

2. Assistant Professor (Cardio vascular Surgery), Department of Cardiac Surgery, NICVD, Dhaka, Bangladesh.

3. Registrar, Dept. of Cardiac Surgery, NICVD, Dhaka, Bangladesh.

4. Professor, Dept. of Cardiac Surgery, NICVD, Dhaka, Bangladesh.

5. Assistant Registrar, Dept. of Cardiac Surgery, NICVD, Dhaka, Bangladesh

6. Assistant Registrar, Dept. of Cardiac Surgery, NICVD, Dhaka, Bangladesh.

7. MS Resident, Dept. of Cardiac Surgery, NICVD, Dhaka, Bangladesh.

Address for Correspondence: Dr. Subhash Chandra Mandal, Associate Professor of Cardiac Surgery, National Institute of Cardiovascular Diseases, Sher-E-Bangla Nagar, Dhaka-1207. Email:subhashchandramandal1962@gmail.com, Phone: 01711456077
Incidence of cardiac tumors ranged from $0.0017 \%$ to $0.33 \%{ }^{(3)}$. Of all cardiac tumors $75 \%$ are benign; $50 \%$ of the benign tumors are myxomas ${ }^{3}$. Grossly myxomas are rounded, oval or polypoid soft gelatinous friable mass having smooth or lobulated surface. Its size may vary from 0.5 to $15 \mathrm{~cm}$ in diameter and is of white, brown or yellowish in colour. Most are pedunculated and some are sessile.Almost all arise from the region of fossa ovalis of interatrial septum and a few from other part of the endothelial surface of the heart ${ }^{3}$.

About $75 \%$ myxomas occur in left atrium and $20 \%$ in right atrium and less than $10 \%$ in ventricles ${ }^{(4)}$ Myxomas can occur at all ages (about 15\% in 1-15 yrs age group) but its incidence is greatest in $3^{\text {rd }}$ to $6^{\text {th }}$ decade. This tumor is of great interest because of its low incidence, protean clinical manifestations, potentially curable form of serious cardiac disease and ease of its diagnosis (only by echocardiography).

NICVD is the parent cardiac institute of Bangladesh and performing all types of cardiac surgery including cardiac

DOI: http://dx.doi.org/10.3329/bhj.v32i2.36093

Copyright $\odot 2017$ Bangladesh Cardiac Society. Published by Bangladesh Cardiac Society. This is an Open Access articles published under the Creative Commons Attribution-NonCommercial 4.0 International License (CC BY-NC). This license permits use, distribution and reproduction in any medium, provided the original work is properly cited and is not used for commercial purposes. 
tumors except Heart transplantation. In NICVD open heart surgery has been started in 1981; since then cardiac myxomas have been resected, along with other cardiac surgery. Initially the surgical incidence of cardiac myxoma was low due to lack of awareness of our population and low socioeconomic conditions and also due to lack of diagnostic facilities in the peripheral hospitals. For the last 17 years the incidence of cardiac myxoma patients in the department of cardiac surgery has increased, may be due to improvement of economic solvency and awareness of people, increasing diagnostic facilities all over the country and good surgical outcome.

But there is no documentation or study in the department of cardiac surgery regarding the incidence and status of surgical treatment of cardiac myxoma in NICVD which represent the mother institute of cardiovascular diseases of Bangladesh. So we felt keen interest to perform a study regarding the incidence, age of occurrence, clinicalpresentations, male female ratio of the patients with the disease and status of myxoma surgery at NICVD, Dhaka. This will enable us to compare these parameters with those of other countries and also increase the awareness regarding this serious disease of our medical professionals as well as common people of Bangladesh.

\section{Materials and Methods:}

This study was conducted in the department of cardiac surgery, NICVD, Dhaka, Bangladesh. The period of study was from January 2000 to December 2016. A retrospective observational study was performed. In this study all patients admitted with the diagnosis of cardiac myxoma and underwent surgical excision of the tumour were included. We studied the incidence, male female ratio, age of presentation, clinical presentations, peroperative findings of tumors ( location, attachments and size), perioperative and post operative complications and early (in-hospital and one month following discharge) outcome of surgical treatments.

Diagnosis of myxoma was established by 2D Echocardiography. No patient required TEE or other imaging technique. Operation was undertaken on emergency basis soon after diagnosis to avoid complications (sudden death, stroke, acute limb ischaemia etc). The standard surgical approach was through a median sternotomy; cardiopulmonary bypass (CBP) was stablished with aortic and bicavalcanulation. Myocardial protection was achieved with antegrade cold blood cardioplegia and moderate hypothermia. The surgical approach to left atrial myxoma was through right atrial and transeptal. The tumor was resected completely along with a button of full thickness intratrial septum where the tumor was attached. All four chambers were explored to exclude multicentric origin of tumor and to remove any fragment of tumor by thorough irrigation. Defect created in the interatrial septum was repaired directly with prolene suture or using a pericardial patch. The size of the tumor was measured and recorded and all the tumors were sent for histopathological examinations. During the post-operative period the patients were treated in ICU and then in the wards. All patients came for follow up one month after discharge. They underwent clinical examinations and investigations for blood for $\mathrm{CBC}$, chest $\mathrm{X}$-ray and echocardiogram during the first follow up.

\section{Results:}

129 patients underwent operation for cardiac myxoma during this 17 years period (January 2000 to December 2016) in this institution.

Table- I

Age and sex distribution ofpatients $(n=129)$

\begin{tabular}{lccc}
\hline Age group & Number of patients & Male & Female \\
\hline $20-30$ & $5(04 \%)$ & 3 & 2 \\
$31-40$ & $49(38 \%)$ & 17 & 32 \\
$41-50$ & $56(43 \%)$ & 21 & 35 \\
$51-60$ & $19(15 \%)$ & 4 & 15 \\
\hline Total & & $45(35 \%)$ & $84(65 \%)$ \\
\hline
\end{tabular}

45 patients $(35 \%)$ were male and 84 patients $(65 \%)$ were female. Male female ratio was $1: 1.9$. only $5(04 \%)$ patients were in 20 to 30 years age group and $19(15 \%)$ were in 51 to 60 years of age group. 105 patients ( $81 \%$ ) were distributed into 31 to 50 years of age group. That is, most of the patients were distributed into $4^{\text {th }}$ to $5^{\text {th }}$ decade of life.

Table-II

Clinical presentations of patients $(n=129)$

\begin{tabular}{lcc}
\hline Symptoms & $\begin{array}{c}\text { Number of } \\
\text { patients }\end{array}$ & \\
\hline A. Obstructive symptoms & & \\
$\quad$ (Symptoms of valve obstructions) & 17 & $13 \%$ \\
B. Embolic symptom & 6 & $4.6 \%$ \\
a. Stroke & 5 & $03.8 \%$ \\
b.Acute limb ischaemia & 1 & $0.8 \%$ \\
C. Constitutional symptoms & 5 & $3.8 \%$ \\
D. Mixed & 101 & $78.3 \%$ \\
a.Constitutional plus embolic & 02 & $1.6 \%$ \\
b.Constitutional plus obstruction & 99 & $76.7 \%$ \\
\hline
\end{tabular}

17 patients (13\%) presented with intermittent mitral/tricuspid valve obstructive symptoms. $6(4.5 \%)$ patients presented with embolic features; of these, 5 patients $(03.8 \%)$ presented with stroke and 1 patient $(0.8 \%)$ presented with amputation 
due to acute right lower limb ischaemia. 5 patients $(6 \%)$ presented with only constitutional symptoms. 101 patients (78\%) presented with mixed symptoms. Of these, 99 patients $(76.7 \%$ of all) presented with both obstructive and constitutional symptoms and, 2 patients $(1.6 \%)$ had features of both stroke and constitutional symptoms.

Table-III

Distribution of Myxomas in cardiac chambers. $(n=129)$

\begin{tabular}{lcc}
\hline Name of Cardiac chambers & $\begin{array}{c}\text { Number of } \\
\text { patients }\end{array}$ & Percentages \\
\hline Right atrium & 14 & $11 \%$ \\
Left atrium & 112 & $86.6 \%$ \\
Multicentric(Biatrial) & 02 & $1.6 \%$ \\
Right Ventricle & 01 & $0.8 \%$ \\
Left ventricle & 00 & $00 \%$ \\
\hline Total & 129 & $100 \%$ \\
\hline
\end{tabular}

112 patients(86.6\%) had left atrial myxoma and only 14 patients(11\%) had right atrial myxoma. 2 patients had multicentric (biatrial) myxoma and 1(one) patient had myxoma originated in the right ventricle. 124 myxomas were attached to the interatrial septum in the region of Fossa ovalis and only 5 ones were attached in the other parts of the endothelial surface of the atria. Among all,114myxomaswere pedunculated and 15 were sessile. The size of the myxomas ranged from $3 \mathrm{~cm}$ to $12 \mathrm{~cm}$ in maximum diameter.

Table IV

Postoperative complications and mortality $(n=129)$

\begin{tabular}{lc}
\hline Name of Complication & Number $(\%)$ \\
\hline Superficial sternal wound infection & $5(3.88 \%)$ \\
Pleural effusion & $3(2.33 \%)$ \\
Supraventricular arrhythmia & $3(2.33 \%)$ \\
Reexploration for bleeding & $2(1.55 \%)$ \\
Prolonged Ventilations & $4(3.10 \%)$ \\
Death & $3(2.33 \%)$ \\
\hline
\end{tabular}

Peroperative embolization did not occur in any patient. 17patients developed postoperative complications which were managed accordingly and then all were discharged in sound condition. Three patients died in ICU, one due to low output syndrome(LOS) and two due to respiratory failure,predispose by severe poor general condition.

\section{Discussion:}

Cardiac myxoma constituted $1.08 \%$ of the total open heart surgery during this period of 17 years(January 2000 to
December 2016). This figure is about thrice the reported results in the literature (approx $0.3 \%)^{(5)}$. In our study incidence in the female sex is higher similar to the reports in many other studies ${ }^{(6-7)}$. Our patients confirmed age distribution as evident in other series ${ }^{(8)}$.

In most series ratio of the tumor occurrence in the left and right atria is nearly $7: 2$.But in our study it is $8: 1$ that is, more than 2 times greater. Size range of myxoma is similar to most other studies. Myxoma patients presented with one or more of the triad of intracardiac obstruction, embolism and constitutional symptoms. In our study most patients $99(76.7 \%)$ presented with combination of constitutional and intracardiac obstructivesymptoms ${ }^{(9-4)}$. A higher frequency of embolization (30-40\%) was reported in western series but in our study it is merely $8(6 \%)$.

Like most centers we approached LA myxoma through right atrial and transseptal route. This allowed good exposure and viewing all four cardiac chambers. Only one surgeon used Left atriotomy to excise LA myxoma. During excision of RA myxoma we applied another cross clamp across MPA to prevent peroperative pulmonary embolism.

We could not maintain prolong follow up to monitor recurrence of tumor. We studied only early outcome (upto one month following discharge: first follow up). But no surgeon reported any patient presented with recurrence of the disease locally or at remote organ. Post operative complications were almost similar to other series ${ }^{(5-10)}$.

\section{Conclusions:}

Cardiac myxomas form a very small percentage of cardiac diseases. Most myxomas in our population arise in LA. Immediate surgical treatment is indicated in all patients to prevent sudden death and embolic complications. This tumor can be excised with low rate of morbidity and mortality. Early outcome of myxomas surgery in our centre is excellent and is of international standard.

\section{References:}

1. Mac GSW, Sidhy P, Aherne T, Luke D, Wood AE, Neligan MC. Atrial Myxoma:National incidence, diagnosis and surgical management. Isr J Med Sci. 1993;162:223-6.

2 .DePace NL, Soulen RL, Kotler MN, Mintz GS. Two dimensional echocardoigraphic detection of intraatrial masses. Am J Cardiol. 1981;48: 954—60.

3. Wold LE, Lie JT. Cardiac myxomas: a clinicopathologic profile. Am J Pathol.1980;101: 219-40. 
4. Bjessmo S, Ivert T. Cardiac myxoma : 40 years experience in 63 patients. Ann Thorac Surg. 1997;63:697-700.

5. Castells E, Ferran V, Octavio de TMC, Calbet JM, Benito M. Cardiac myxomas: surgical management, long term results and recurrence. J Cardiovasc Surg (Torino).1993;34:49-53.

6. Reynen K. Cardiac Myxoma. N Engl J Med. 1995;333(24): 1610-7.

7. Pinede L, Duhaut $P$, Loire $R$. Clinical presentation of left atrial cardiac myxoma :a series of 112 consecutive cases. Medicine. 2001;80(3):159-72.
8. Khan MA, Khan AA, Waseem M. Surgical experience with cardiac myxoma. J Ayub Med Coll Abbottabad.2008;20(2):76-9.

9. Burke AP, Virmani R. Cardiac myxoma. A Clinicopathologic study.Am J Clin Pathol.1993;100:671-80.

10. Keeling IM, oberwalder P, Anneli MM, Schuchlenz H, Demel U, Tilz GP, et al. Cardiac Myxomas: 24 years of experience in 49 patients. Eur J Cardiothorac Surg. 2002;22:971-7. 